\title{
Comprensión, competencia y logro en la educación artística escolar
}

\section{Understanding, competence and achievement in the school-based art education}

\author{
PABlo LeKue-RodRÍGUeZ \\ Departamento de Didáctica de la Expresión Musical, Plástica y Corporal. \\ Escuela Universitaria de Magisterio de Vitoria/Gasteiz. \\ pablo.lekue@ehu.es
}

Recibido: 27 de junio de 2013

Aprobado: 10 de abril de 2014

\begin{abstract}
Resumen
El presente trabajo estudia la comprensión artística de un grupo de 606 estudiantes de Educación Primaria y de Educación Secundaria en relación a su competencia artística autopercibida y en relación al logro artístico en Educación Artística. Se establecen dos objetivos, primero identificar las áreas definidas por la investigación previa para la comprensión artística (social, histórica, estética, pedagógica y biográfica) así como identificar los cuatro niveles consecutivos de complejidad para cada área (ingenuo, principiante, aprendiz y maestro). El segundo objetivo es analizar la comprensión artística y el rendimiento artístico en el aula de arte. Se formulan dos hipótesis que asumen relación positiva y significativa de la comprensión artística con, primero, la edad y el sexo de los sujetos y, segundo, con la autopercibida competencia artística y con el logro artístico en educación artística. Dichas hipótesis resultan precisadas por los resultados pues la comprensión artística sí es mejor entre las chicas y aumenta con la edad hasta los 15 años, aunque a partir de esa edad las diferencias entre grupos de edad resultan no significativas. La autopercibida competencia artística en el aula disminuye con la comprensión artística y el logro artístico aumenta conforme aumenta dicha comprensión artística.
\end{abstract}

Palabras clave: educación artística, comprensión, competencia artística, logro artístico.

Lekue-Rodríguez, P. (2014): Comprensión, competencia y logro en la educación artística escolar. Arte, Individuo y Sociedad, 26(3) 401-418

\begin{abstract}
This paper studies the artistic understanding of a group of 606 Primary and Secondary school students in relation to their self-perceived artistic competence and in relation to their academic achievement in Art Education. Two aims were established: first, to identify the areas which previous research defines for the artistic understanding (social, historical, aesthetic, pedagogic and biographical understanding) and the four consecutive levels of complexity for every area (naive, novice, apprentice and master). The second aim is to analyze artistic understanding and academic achievement in art education class. The two initial hypotheses established assume a significant positive relationship between artistic understanding and, firstly, the subjects' age and gender, and secondly, their self-perceived artistic competence and their academic achievement in art education. These hypotheses were further clarified by the results. The artistic understanding is better among the girls and it increases with the age until the students are 15 years old. Then the differences between this age group and the other age groups become non-significant. Self-perceived artistic competence in the classroom declines according to the artistic understanding while the artistic achievement rises according to the artistic understanding.
\end{abstract}

Keywords: art education, understanding, artistic competence, artistic achievement. 
Lekue-Rodríguez, P. (2014): Understanding, competence and achievement in the school-based art education. Arte, Individuo y Sociedad, 26(3) 401-418

Sumario: 1. La comprensión, la competencia y el logro artísticos en la educación artística, 1.1. La comprensión artística, 1.2. La competencia artística autopercibida, 1.3. El logro artístico, 2. Método. 2.1. Objetivos, 2.2. Hipótesis, 2.3. Variables e Instrumentos, 2.3.1. La comprensión artística, 2.3.2. Competencia artística autopercibida, 2.3.3. El logro artístico, 2.4. Participantes, 2.5. Procedimiento, 3. Resultados, 3.1. Comprensión artística histórica, 3.2. Comprensión artística social, 3.3. Comprensión artística estética, 3.4. Comprensión artística pedagógica, 3.5. Comprensión artística biográfica, 3.6. Comprensión y competencia artísticas según el sexo de los sujetos, 3.7. Comprensión y competencia artísticas según el sexo de los sujetos, 4. Discusión, 5. Conclusiones. Referencias.

\section{La comprensión, la competencia y el logro artísticos en la educación artística}

\subsection{La comprensión artística}

La comprensión de un tópico se entiende como la capacidad de explicar, justificar, extrapolar, vincular y aplicar de maneras que van más allá del conocimiento y la habilidad rutinaria (Perkins, 1997) y, en contextos educativos, es estudiada generalmente buscando medir la asimilación de información a partir de lecturas de textos, de la audición de documentos sonoros y del visionado de audiovisuales que transmiten datos que deben ser retenidos y reproducidos por el alumnado (Gabrelian, Blumberg y Hogan, 2009; Logan, Medford y Hughes, 2010). Otras áreas de conocimiento relacionan la comprensión con determinadas tareas que los estudiantes deben realizar, como transformar los materiales dados, obtener ciertas formas a partir de fragmentos dados, realizar conclusiones sobre los resultados y reflexionar sobre cómo son los materiales y cómo funcionan (Buxkemper y Hartfiel, 2003). Hay quien incorpora la comprensión disciplinar como variable a estudiar en relación al rendimiento académico, en relación a las estrategias de aprendizaje y motivación y en relación a las actitudes hacia la ciencia (Kim y Song, 2010).

Estudios previos han encontrado que la comprensión de los contenidos televisivos por parte de los niños aumenta con la edad. Comienzan identificando objetos y gente a los seis meses y son capaces de comprender e imitar acciones con 24 meses de edad. El niño alcanza la comprensión del adulto cuando llegan a los 13 años de edad (Anderson y Hanson, 2010). En el caso de estos adultos, se utilizan cámaras de fotografía y de vídeo para el registro de imágenes con el objetivo de crear visiones personales de la realidad y para componer historias significativas basadas en la vida cotidiana (Yates, 2010), ya que los relatos sobre las imágenes registradas proporcionan a los fotógrafos la oportunidad de comprender su entorno y su realidad inmediata (Beilin, 2005).

La educación artística promueve el empleo de imágenes para el aprendizaje y la comprensión de valores sociales y culturales que trasciendan las disciplinas escolares (Barbosa, 2005), con el objetivo último de que los jóvenes comprendan la realidad circundante, dotando de sentido las tareas del aula insertándolas en la experiencia vital de cada estudiante (Aznárez, 2008). 
Se ha precisado el concepto de comprensión artística del alumnado alrededor de cuatro niveles consecutivos (ingenuo, de principiante, de aprendiz y de maestría) y en torno a cinco ámbitos (histórico, estético, pedagógico, biográfico y social) (Bernardo y Sueli, 2009; Sueli, 2002). El nivel de comprensión ingenua se caracteriza por unos desempeños basados en el conocimiento intuitivo. Los alumnos describen la construcción del conocimiento como un proceso no problemático consistente en captar información que está directamente disponible en el mundo. En el nivel de comprensión de principiante se interpolan ciertos conceptos disciplinares. La validación de los procedimientos de construcción del conocimiento depende de la autoridad externa más que de criterios racionalmente consensuados desarrollados dentro de las disciplinas o dominios. En el nivel de comprensión de aprendiz, los desempeños están arraigados en el conocimiento disciplinario. El alumnado ve la construcción del conocimiento como algo complejo y, con apoyo, los desempeños descubren la relación entre conocimiento disciplinario y vida cotidiana. El nivel de comprensión de maestría presenta desempeños creativos y críticos que van más allá de demostrar comprensión disciplinaria. El alumnado puede usar el conocimiento para reinterpretar y actuar en el mundo que los rodea (Hetland, Hammerness, Unger y Wilson, 1997).

\subsection{La competencia artística autopercibida}

La percepción de la propia capacidad intelectual se identifica con las destrezas autopercibidas (Chamorro-Premuzic, Harlaar, Greven y Plomin, 2010) y es asimilada a las autoteorías sobre la propia inteligencia o se asocia al autoconcepto académico (Kornilova, Kornilov y Chumakova, 2009). En contextos de aprendizaje, los desempeños son estudiados en relación a la autopercibida habilidad intelectual (Guay, Ratelle, Roy y Litalien, 2010) y en relación a la percepción de la propia inteligencia emocional (Laborde, Dosseville y Scelles, 2010).

Se han encontrado en la investigación previa relaciones positivas de la competencia artística con la edad de los estudiantes (mejor percepción de las propias capacidades artísticas de los más jóvenes), con el sexo de los jóvenes (mejor percepción en las chicas que en los chicos) y con la preparación específica de los profesores (mejor percepción en los que tienen profesorado especialista en arte) (Pavlou y Kambouri, 2007).

\subsection{El logro artístico}

El logro artístico es la calificación obtenida en las tareas artísticas en el aula. El logro académico, en general, se relaciona habitualmente con la puntuación media obtenida en cada asignatura, lo que plantea el problema de su medida estandarizada por las diferencias entre las materias y entre los distintos currículos educativos (Tanilon, Segers, Vedder y Tillema, 2011) y ha sido estudiado en relación a características intelectuales (Colom, Escorial, Chun Shih y Privado, 2007; Kornilova, Kornilov y Chumakova, 2009), motivacionales (Urdan y Schoenfelder, 2006) y personales (Chamorro-Premuzic y Furnham, 2008) del alumnado. 


\section{Método}

\subsection{Objetivos}

2.1.1. Identificar los factores que definen la comprensión artística y su relación con las actuaciones en clase de arte.

2.2.2. Analizar la relación entre la comprensión artística, la competencia artística que se atribuyen a sí mismos los estudiantes y el resultado académico en clase de educación artística.

\subsection{Hipótesis}

2.2.1. Los ámbitos histórico, social, estético, pedagógico y biográfico, de la comprensión artística deben aumentar a medida que la edad de los sujetos es mayor y deben ser mejores entre las chicas.

2.2.2. La comprensión artística se relaciona positivamente con la competencia artística autopercibida y con la calificación final en la asignatura de educación artística.

\subsection{Variables e instrumentos}

\subsubsection{La comprensión artística}

El "Cuestionario para la Comprensión de las Imágenes" pretende establecer los niveles de comprensión de ingenuo, principiante, aprendiz y maestría en relación a una obra de arte, el "Guernica" de Picasso, a partir de una serie de preguntas basadas en dicha pintura y en torno a cinco ámbitos (Sueli, 2002): el histórico (relaciones que el espectador establece entre la obra de arte y el contexto histórico), estético (criterios del espectador para considerarla como obra de arte), pedagógico (relación de la obra con otras asignaturas del currículo), biográfico (relación de la obra con la biografía personal del espectador) y social (relación de la obra con acontecimientos contemporáneos al espectador).

\subsubsection{Competencia artística autopercibida}

Es la confianza en las propias destrezas artísticas y pretende ser medido mediante ocho ítems que forman parte del cuestionario "Attitude Scale for Art Experienced in School" (Pavlou y Kambouri, 2007), que mide las actitudes de los estudiantes hacia la educación artística en el aula.

\subsubsection{El logro artístico}

Se recaban las calificaciones finales del alumnado en el área de Educación Artística con rango entre uno y diez. 


\subsection{Participantes}

Han participado en esta investigación 606 alumnos y alumnas de quinto y sexto de Educación Primaria así como de los cuatro cursos de Educación Secundaria, todos ellos en edades comprendidas entre los diez y los 17 años, pertenecientes a centros educativos tanto públicos como concertados del País Vasco.

\begin{tabular}{|c|c|c|c|c|c|c|c|c|c|c|c|}
\hline & \multicolumn{3}{|c|}{ EDAD } & \multicolumn{3}{|c|}{ NIVEL ACADÉMICO } & \multicolumn{2}{|c|}{ SEXO } & \multicolumn{2}{|c|}{ IDIOMA } & \\
\hline & $\begin{array}{l}10- \\
12\end{array}$ & $\begin{array}{c}13- \\
14\end{array}$ & $\begin{array}{l}15- \\
17\end{array}$ & $\begin{array}{c}3^{\circ} \text { ciclo } \\
\text { Primaria }\end{array}$ & $\begin{array}{c}1^{\mathrm{o}} \text { ciclo } \\
\text { Secundaria }\end{array}$ & $\begin{array}{c}2^{\circ} \text { ciclo } \\
\text { Secundaria }\end{array}$ & chicos & chicas & español & vasco & TOTAL \\
\hline $\mathbf{N}$ & 256 & 239 & 111 & 248 & 204 & 154 & 287 & 319 & 225 & 381 & 606 \\
\hline$\%$ & 42.2 & 39.4 & 18.4 & 40.9 & 33.7 & 25.4 & 47.4 & 52.6 & 37.1 & 62.9 & 100 \\
\hline
\end{tabular}

Tabla 1. Participantes.

\subsection{Procedimiento}

En una primera fase del estudio se han buscado estudios previos sobre comprensión, sobre la competencia artística y sobre el logro artístico, así como sobre estudios que pudieran haber analizado dichas características en conjunto y en contextos educativos.

Una segunda fase consiste en el diseño del cuestionario a partir de la investigación previa (Sueli, 2002). Se adaptan, se traducen o se redactan los ítems y se presentan en forma de pregunta abierta para solicitar del alumnado, además del "sís" o del "no", la respuesta razonada que permitirá la categorización posterior.

La tercera fase se desarrolla en los centros escolares mediante citas concertadas con el profesorado de Educación Primaria y de Educación Secundaria. Se accede a las aulas y se proporciona a cada alumno una reproducción del cuadro "Guernica", realizado en 1937 por Pablo Picasso, por encargo del gobierno republicano español en el exilio y tras el bombardeo de la ciudad vasca de Gernika por la Legión Cóndor al servicio del bando nacional comandado por Franco.

A continuación, se suministra al alumnado el cuestionario de cinco preguntas abiertas en relación a la imagen del cuadro, una pregunta por cada uno de los cinco ámbitos de la comprensión artística. La primera pregunta pretende averiguar el conocimiento de los jóvenes sobre el hecho histórico del bombardeo de Gernika, la denominada comprensión histórica (“¿para qué crees que han hecho la imagen?"). La segunda pregunta indaga en las relaciones que establecen los jóvenes del hecho histórico con la realidad contemporánea (“¿qué sucede / qué cuenta la imagen?”), la que se denomina comprensión social. La tercera pregunta plantea cuáles son las categorías estéticas que los jóvenes emplean al referirse a un cuadro reconocido como obra de arte y como testimonio de un acto bélico (“¿colocarías la imagen en un museo?”), la 
comprensión artística. La cuarta pregunta (“¿para qué podría servirte la imagen?”) busca desvelar la utilidad atribuida a la imagen del "Guernica" como herramienta de aprendizaje en contextos educativos, la llamada comprensión pedagógica. La quinta y última pregunta busca conectar la realidad narrada en imágenes con la realidad de cada espectador, haciendo reflexionar a los jóvenes sobre la realidad representada que se les muestra, la conocida como comprensión biográfica. Es importante destacar que las cinco preguntas reclaman la respuesta razonada que es lo que debe permitir su posterior clasificación en los niveles de comprensión.

En una cuarta fase, una vez recolectados los cuestionarios, se procede a la codificación de las respuestas en función de los ámbitos de comprensión (histórico, social, artístico, pedagógico y biográfico) y en función de los niveles de comprensión (ingenuo, principiante, aprendiz y maestría) descritos en la investigación previa (Sueli, 2002). Se atribuye, en cada ámbito de comprensión, un uno (nivel de comprensión ingenua) a aquellas respuestas consideradas irreflexivas, erróneas o no razonadas ("sí", "no"). El número dos (nivel de comprensión de principiante) es para las respuestas que se apoyan en consideraciones disciplinares de autoridad ("lo ha hecho alguien que es un artista famoso"). El número tres (nivel de comprensión de aprendiz) señala las respuestas que establecen relaciones entre el conocimiento disciplinar y la realidad representada ("se trata de un hecho histórico"). El número cuatro (nivel de comprensión de maestría) debe señalar el grado máximo de comprensión artística y debe mostrar un conocimiento crítico que trascienden el propio entorno escolar.

En una quinta fase, se realiza el procesamiento informático de los datos y, dado que las muestras no cumplen la condición de normalidad para ninguna de las variables consideradas, se aplican las pruebas no paramétricas en el análisis de la varianza, en concreto la prueba de Kruskal-Wallis y, para las posteriores comparaciones grupo con grupo, se realiza la prueba de Mann-Whitney (Norusis, 2002).

Únicamente se han considerado para el estudio de la comprensión artística las respuestas proporcionadas por los sujetos que han respondido las cinco preguntas del cuestionario y que han sido 397 individuos, que se han agrupado en tres grupos de comprensión artística.

El nivel ingenuo o de comprensión baja consta de 129 individuos; el nivel de principiante o de comprensión media está constituido por 196 individuos y el nivel de aprendiz o de comprensión alta tiene 72 personas, representando el 32.5 por ciento, el 49.4 por ciento y el 18.1 por ciento del total, respectivamente.

No se ha establecido el nivel superior de maestría, que presenta desempeños creativos y críticos que van más allá de demostrar comprensión disciplinaria, para ninguno de los sujetos que han respondido al cuestionario sobre comprensión artística y dicho cuestionario permite obtener un mínimo de cinco puntos, un punto por cada uno de los cinco ámbitos, y una puntuación máxima de 15 puntos, tres puntos por cada uno de los ámbitos. La tabla 2 muestra, a continuación, el número $(\mathrm{N})$ de sujetos en cada nivel de comprensión artística y en cada ámbito de dicha comprensión junto al porcentaje sobre el total, 397 estudiantes que, de un total de 606 alumnos, son los que han respondido íntegramente a las cinco preguntas del cuestionario. 


\begin{tabular}{|c|c|}
\hline \multicolumn{2}{|c|}{ COMPRENSIÓN ARTÍSTICA } \\
\hline NIVELES & $\begin{array}{c}\text { ÁMBITOS } \\
\text { Histórico, } \\
\text { Social, } \\
\text { Estético, } \\
\text { Pedagógico, } \\
\text { Biográfico }\end{array}$ \\
\hline Baja / Ingenua & $\mathrm{N}=129(32,5 \%)$ \\
\hline Media / Principiante & $\mathrm{N}=196(49,4 \%)$ \\
\hline Alta / Aprendiz & $\mathrm{N}=72(18,1 \%)$ \\
\hline Muy Alta / Maestría & $\mathrm{N}=0(0 \%)$ \\
\hline Total & $\mathrm{N}=397(100 \%)$ \\
\hline
\end{tabular}

Tabla 2. Comprensión artística: número de casos y porcentaje del total según niveles y ámbitos de comprensión.

\section{Resultados}

Con objeto de analizar la comprensión artística en la escuela de Educación Primaria y de Educación Secundaria, se presentan por ámbitos las respuestas-tipo obtenidas en el cuestionario para la comprensión de las imágenes. Para las comparaciones entre las medias por grupos de edad, se han establecido tres grupos entre los sujetos del estudio, el grupo entre diez y 12 años, el grupo entre 13 y 14 años y el grupo entre 15 y 17 años. La figura 1 resume esta comprensión por ámbitos según edad y sexo.



Figura 1. Comprensión artística en jóvenes según el nivel, según los ámbitos y según el sexo. 
La figura 1 muestra que la comprensión artística aumenta según lo hace la edad de los estudiantes, hasta el grupo de edad de 13-14 años, donde se produce un descenso en todos los ámbitos de la comprensión, excepto en la denominada comprensión artística biográfica, que continúa aumentando. Las diferencias en todos los ámbitos de la comprensión artística entre chicos y chicas son evidentes y favorables a ellas.

A continuación se presentan los resultados sobre comprensión artística por ámbitos (histórico, social, artístico, pedagógico y biográfico) y según niveles de comprensión (ingenuo, principiante y aprendiz).

\subsection{Comprensión artística histórica}

Por comprensión histórica se entienden las relaciones que el espectador establece entre la obra de arte, y su contexto histórico. Mediante la pregunta del cuestionario, "¿Para qué crees que han hecho esta imagen?" se pretende, en este sentido, indagar en el conocimiento del alumnado sobre el momento histórico en que surgió el "Guernica" y las razones que originaron esta obra.

El nivel ingenuo se manifiesta en respuestas irreflexivas a la obra y los sujetos responden con sintéticos "ni idea", "no sé", extravagantes "que todo el mundo está loco", curiosos "para ganar dinero", "para entretenerse" o evidentes "para que veamos a los animales".

El nivel de principiante refleja un conocimiento disciplinar basado en juicios de autoridad y sin conexiones con la realidad social, respondiendo a esa misma pregunta "para expresar sus pensamientos", "para expresar sus sentimientos" o "para mejorar su forma de dibujar". Si en alguna ocasión se trasciende la propia imagen, las referencias a hechos históricos o contemporáneos son vagas, "para enseñar a la gente [lo] que pasaba hace mucho", "para ver cómo es el mundo", "para que la gente vea lo que hay en otros sitios" o evidentemente erróneas "para representar la segunda guerra mundial", "para representar la ciudad de Sevilla".

En el nivel de aprendiz se establecen conexiones de la obra con el contexto histórico que dio lugar a ella. Así, "para representar el bombardeo de Gernika", "para saber qué sucedió en Gernika"; "para expresar la matanza sucedida en Gernika"; "para recordar a las víctimas de Gernika en la guerra civil"; "para contar lo qué ocurrió en Gernika el día que lo bombardearon los nazis".

La comprensión artística histórica establece diferencias entre los grupos de edad que resultan significativas aunque de forma irregular pues la media asciende entre el grupo de 10-12 años (1.7) y el de 13-14 años (2.0), para descender en el grupo de 15-17 años (1.9) (cf. fig. 1). La posterior comparación grupo con grupo, mantiene las apuntadas diferencias entre el grupo de 10-12 años y el grupo de 13-14 años, no existiendo otras diferencias en el resto de posibles comparaciones entre grupos de edad en la comprensión artística histórica.

\subsection{Comprensión artística social}

El ámbito de comprensión social alude al modo en que los espectadores de una obra la relacionan con realidades contemporáneas de la sociedad en que viven buscando aquello del suceso representado que bajo diferentes formas pudiera pervivir en la 
actualidad. Mediante dos preguntas, “¿Qué sucede en la imagen?” y “¿Qué cuenta la imagen?", se busca analizar si el estudiante es capaz de establecer dichos nexos, para lo que se solicita tanto la descripción de lo percibido como la narración del propio hecho histórico del bombardeo.

En el nivel ingenuo se responde con "no sé", "que los toros matan a la gente", "no creo que sea un acontecimiento concreto", "que se junta todo", "las guerras púnicas de Grecia", "una pelea / nada".

En el nivel de principiante se generalizan el suceso. Así: "representa los estragos de una guerra y el dolor de la gente"; "hay gente pobre y herida, puede ser por una guerra", "que la gente se está muriendo".

En el nivel de aprendiz se encuentran la relación con el hecho concreto que originó la obra, "se explica el bombardeo ocurrido en Gernika"; "representa qué ocurrió en Gernika en la época del bombardeo / que los de Gernika lo pasaron mal".

El ámbito social de la comprensión artística establece diferencias estadísticamente significativas entre los grupos de edad. Asciende la media entre el grupo de 10-12 años (1.6) y el inmediato grupo de 13-14 años (1.8) para descender en el grupo de edad de 15-17 años (1.7) (cf. fig. 1). La prueba grupo con grupo señala que dichas diferencias son significativas entre el grupo de 10-12 años y el de 13-14. No sucede lo mismo entre el grupo de 10-12 y el de 15-17 años, ni entre los grupos de 13-14 y 15-17 años, ninguno de los cuales pueden diferenciarse significativamente en función de la comprensión artística histórica.

\subsection{Comprensión artística estética}

El ámbito de comprensión estético hace referencia a los códigos simbólicos contemporáneos a la obra y, por extensión, a cuáles son las consideraciones del espectador actual de una obra artística para valorarla como merecedora del estatus de patrimonio cultural. Se pretende, mediante la pregunta "¿Colocarías esta imagen en un museo? ¿Por qué?", indagar en los criterios del espectador para calificar el "Guernica" como obra emblemática o como patrimonio colectivo digno de estar en un museo.

En el nivel ingenuo se sitúan las razones dadas tanto a la respuesta afirmativa como a la negativa: la respuesta no razonada "sí"; aquellas respuestas basadas en el gusto personal, "sí, porque me gusta cómo está expresado"; "no, porque no me gusta", "sí, porque es entretenida"; o "sí, porque me parece muy interesante".

En el nivel de principiante se emplean criterios disciplinares que pretenden elevar el gusto personal al rango de categoría estética: "sí, porque es bonita"; "no, porque es fea", o emplean criterios disciplinares: "sí, porque es Arte"; "sí, porque la forma en la que está pintado es muy artística"; o criterios de autoridad: "sí, porque es de Picasso"; "sí, porque es famosa". En ocasiones, el sujeto conoce la realidad de la obra y responde con un escueto, "sí, porque ya está [en un museo]".

En el nivel de aprendiz se establecen conexiones con el hecho histórico concreto que, por encima de criterios de belleza, otorga a la obra la función de testimonio de lo ocurrido, "sí, para expresar lo ocurrido en Gernika"; "sí, porque este cuadro trasmite una historia real y considera que todas las historias reales se han de conocer".

Los resultados de la comprensión artística estética por grupos de edad no 
establecen diferencias entre las puntuaciones medias de los grupos de edad, los tres grupos puntúan igual (1.9) (cf. fig. 1).

\subsection{Comprensión artística pedagógica}

El ámbito de comprensión artística pedagógica aborda lo que enseña la obra, qué se puede aprender de ella en relación a otras disciplinas curriculares o cuál puede ser su utilidad como mediadora del aprendizaje. En contextos educativos se pretende la percepción de utilidad de las imágenes que, más allá de meros accesorios bellos que apelan a los sentimientos, pueden servir al espectador para la construcción de conocimiento. He aquí alguna de las respuestas a la pregunta "¿Para que podría servirte la imagen?".

En el nivel ingenuo: "para responder las preguntas de abajo"; "no lo sé yo, creo que para nada"; "para expresar mis sentimientos".

En el nivel de principiante las respuestas son disciplinares y de autoridad: "para conocer los sentimientos de Picasso"; algunas utilizan criterios estéticos: "no lo sé, para ponerla en la pared de mi casa y decorar"; otras son genéricas: "para reflexionar"; "para pensar"; "para expresar sentimientos".

En el nivel de aprendiz las relaciones con el suceso están presentes y, en este sentido, la obra sirve para entender lo ocurrido: "para comprender lo que sintieron en Guernica".

La comprensión artística pedagógica establece diferencias significativas entre grupos de edad (cf. fig. 1). El grupo de edad inferior, 10-12 años, puntúa el que más bajo (1.6) en la mencionada comprensión artística pedagógica, el grupo siguiente, 13-14 años, puntúa el que más alto (1.8) y para el grupo superior, 15-17 años, la puntuación vuelve a descender a 1.7. Estas diferencias deben ser matizadas en las comparaciones de cada grupo con cada uno de los otros dos. Así, mientras que el grupo de edad de 10-12 años se diferencia de modo significativo del grupo de 13-14 años, no ocurre lo mismo entre el grupo de 10-12 años y el de 15-17 años, ni entre el grupo de 13-14 y el grupo de 15-17 años, cuyas diferencias no son significativas en lo referente a la comprensión artística pedagógica.

\subsection{Comprensión artística biográfica}

La comprensión artística señala la construcción de significados a partir de una imagen, con lo que las posibles relaciones de las obras con experiencias vitales del espectador deben señalar los distintos niveles de comprensión artística biográfica. El ámbito de comprensión biográfico es el que pone en relación la obra artística con la biografía de cada espectador, en qué medida es capaz éste de establecer conexiones entre una realidad representada y la propia experiencia vital. En este mismo sentido, la consideración de unas imágenes concretas como relatos basados en la realidad y no como meras historias inventadas debería indicar altos niveles de comprensión para lo que se formula la pregunta 16, ¿Dirías que son personajes de ficción?”.

En el nivel ingenuo, las respuestas-tipo son: "no sé"; "no, porque no las conozco"; "sí, porque no lo creo"; "sí, porque me parece"; "no, porque son humanos".

En el nivel de principiante, las razones están basadas en aspectos formales 
percibidos: "no, porque tienen forma rara abstracta"; "sí porque son diferentes a los demás".

En el nivel de aprendiz subyacen referencias al hecho real: "no, porque el cuadro está basado en hechos reales", "no, porque todo sucedió en la vida real" o "no porque es un hecho histórico".

Las diferencias entre grupos de edad según la comprensión artística biográfica, resultan en principio significativas. Aumenta progresivamente la puntuación media entre el grupo de 10-12 años (1.6), el grupo de 13-14 años (1.8) y el grupo de 15-17 años (1.9) (cf. fig. 1).

Las mencionadas diferencias son confirmadas en parte por la posterior comparación grupo con grupo, donde se señala que las diferencias entre el grupo de 10-12 años y el de 13-14 años son significativas en lo referido al ámbito biográfico de la comprensión artística. No es posible sin embargo establecer diferencias relevantes del grupo de edad de 15-17 años, ni con el grupo de 10-12 años, ni con el grupo de edad de 13-14 años, en lo que respecta a la comprensión artística biográfica.

En definitiva, en lo referido a la primera hipótesis, que postulaba una relación significativa y positiva entre los ámbitos de la comprensión artística y la edad de los sujetos, los resultados matizan y especifican dicha relación.

Los ámbitos de la comprensión artística histórico, social, pedagógico y biográfico, señalan diferencias estadísticamente significativas entre el grupo de edad de 10-12 y el grupo de 13-14 años, no apareciendo dichas diferencias relevantes entre del grupo de 15-17 años y ninguno de los otros dos grupos de edad, para ninguno de los ámbitos de la comprensión artística. Por su parte, los resultados obtenidos en la denominada comprensión artística estética, no permiten establecer diferencias relevantes entre ninguno de los grupos de edad.

La segunda parte de la primera hipótesis postula diferencias significativas en la comprensión artística atendiendo al sexo de los sujetos y se plantean mejores niveles de comprensión en las chicas.

\subsection{Comprensión y competencia artísticas según el sexo de los sujetos}

Las chicas de Educación Primaria y Secundaria obtienen mejores niveles medios (9.2) de comprensión artística que los chicos (8.7). Dichas diferencias resultan ser significativas y congruentes con la investigación previa que había hallado mejor rendimiento artístico en las chicas en el aula de arte (Pavlou y Kambouri, 2007).

La competencia artística autopercibida es otro factor que debe ser analizado según el sexo de los estudiantes, mostrando los resultados obtenidos que dicha competencia artística autopercibida por chicos y chicas de Educación Primaria y Secundaria es sensiblemente mejor en las chicas (2.8) que en los chicos (2.6).

La figura 2 muestra, a continuación, la distribución de la comprensión artística y la distribución de la competencia artística autopercibida en los chicos y en las chicas respectivamente. 


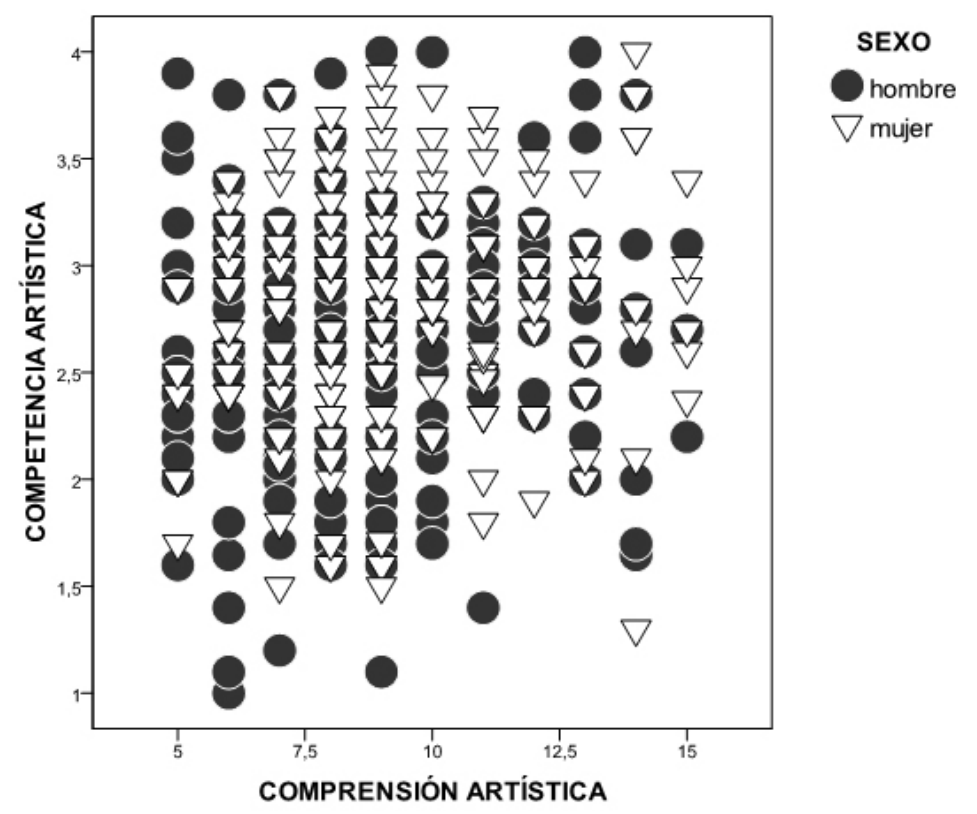

Figura 2. Comprensión y competencia artísticas de los jóvenes según el sexo.

En dicha figura 2 se muestran unos niveles generales medios (concentración mayoritaria de puntos en la zona central del gráfico) de comprensión artística y de competencia artística autopercibida en los chicos y en las chicas, si bien es posible colegir unos mayores niveles de competencia artística (eje Y del gráfico) y unos mayores niveles de comprensión artística (eje X del gráfico) en ellas que en ellos.

\subsection{La comprensión artística, la competencia artística autopercibida y el logro artístico en educación artística}

La segunda hipótesis plantea la relación significativa y positiva de la comprensión artística con la competencia artística percibida y con el logro en educación artística. Se plantean las correlaciones entre las tres variables para verificarlo y se comprueba que existen relaciones positivas y significativas entre la comprensión artística, la competencia artística y el logro académico en educación artística (cf. fig. 3). 


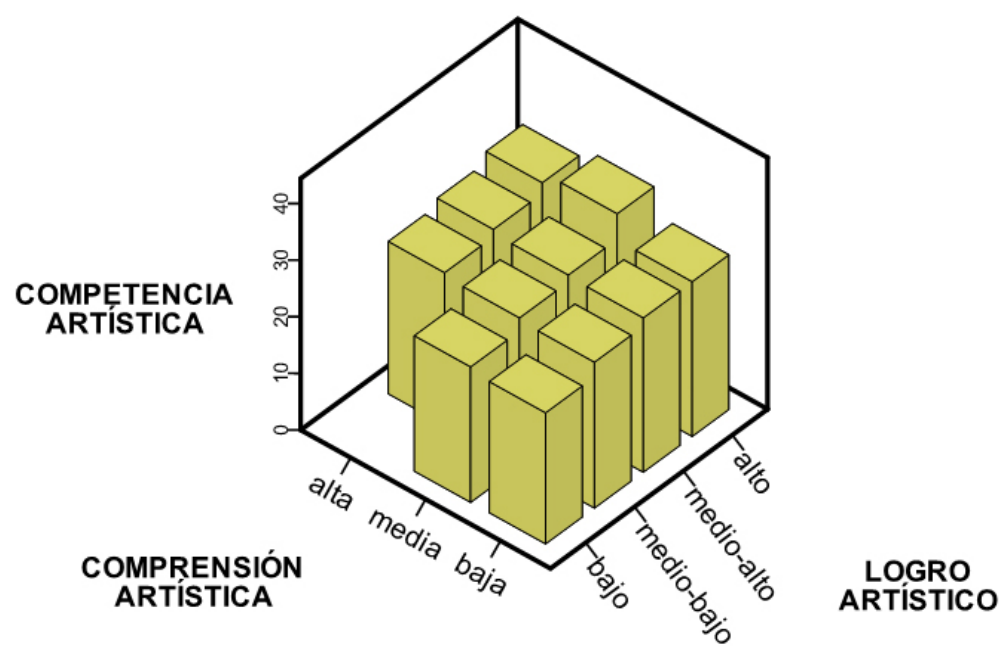

Figura 3. Correlaciones entre comprensión artística, competencia artística autopercibida y el logro artístico.

La figura 3 descubre la mencionada correlación entre las tres variables objeto de estudio. Niveles bajos de logro artístico mantienen relación con niveles bajos de comprensión artística y con niveles bajos de competencia artística autopercibida. En la medida que los niveles en cada una de esas características aumentan, dichos niveles se incrementan también en las otras dos características.

Se compara a continuación la comprensión artística con, respectivamente, la competencia artística autopercibida y con el logro en la asignatura de arte (cf. fig. 4).



Figura 4. . La comprensión artística según la competencia artística autopercibida y según el logro artístico. 
La competencia artística autopercibida disminuye a medida que la comprensión artística aumenta, estableciendo una relación negativa entre ambos factores. El grupo de comprensión artística baja presenta el mayor nivel medio de competencia artística autopercibida (2.8), el grupo de comprensión artística media presenta un nivel medio menor de competencia artística (2.7) y aun desciende dicho nivel medio de competencia artística entre el alumnado con mayores niveles de comprensión (2.6).

Estas diferencias entre grupos de comprensión artística son parcialmente confirmadas en las comparaciones grupo/grupo donde se hallan diferencias significativas de la comprensión artística baja con la comprensión media y con la comprensión artística alta.

En la figura 4 dicha tendencia se representa mediante la aparición de casos de comprensión artística baja junto a niveles medio-altos de competencia artística autopercibida, al tiempo que se observan niveles altos de comprensión artística junto a niveles medio-bajos de competencia artística autopercibida.

La comprensión artística establece, sin embargo, diferencias entre los grupos de calificación en el área de forma positiva y significativa (cf. fig. 4). Al contrario de lo sucedido entre comprensión y competencia artísticas, el grupo de calificación baja obtiene la puntuación media más baja (7.4) en comprensión artística. El grupo de calificación medio-baja puntúa algo más en comprensión (8.3), el grupo de calificación medio-alta aumenta algo (9.6) en comprensión artística y, finalmente el grupo de calificación alta obtiene los mejores resultados medios en comprensión artística (9.9).

Dichas diferencias son precisadas por las correspondientes pruebas grupo con grupo. Así, el grupo de calificación baja se diferencia significativamente del grupo de calificación medio-alta y del grupo de calificación alta, a la vez que, el grupo de calificación medio-baja, se diferencia del grupo de calificación medio-alta y del grupo de calificación alta. Únicamente los dos grupos inferiores de calificación, el grupo de calificación baja y el de calificación medio-baja y los dos grupos de calificación superiores, el grupo de calificación medio-alta y el grupo de calificación alta, no pueden ser diferenciados significativamente en función de la puntuación obtenida en la comprensión artística.

De nuevo la figura 4 ilustra la mencionada relación positiva entre comprensión artística y logro (calificación) artístico. Así, los casos de comprensión alta se sitúan en niveles medio-altos de logro artístico. La comprensión artística baja aparece principalmente alineada con niveles medios de logro. La comprensión artística media se distribuye homogéneamente según sea el logro artístico si bien se relaciona especialmente con niveles medios de logro, todo lo cual sustenta en gran medida la segunda hipótesis que planteaba la relación positiva y significativa entre el logro artístico y la comprensión artística.

\section{Discusión}

Los cinco ámbitos de la comprensión artística ofrecen irregulares resultados en el presente trabajo, pues cuatro dimensiones de dicha comprensión, comprensión artística histórica, social, pedagógica y biográfica, establecen diferencias entre los jóvenes según la edad de estos, si bien no de forma progresiva.

Dichas diferencias son de signo positivo aunque inconstante en tres de ellas, 
las relaciones que el espectador establece entre la obra de arte, y su contexto histórico (la comprensión artística histórica), la comprensión social (el modo en que los espectadores de una obra la relacionan con realidades contemporáneas) y la comprensión pedagógica (cuál puede ser la utilidad de una imagen como mediadora del aprendizaje y en relación a otras disciplinas curriculares). En estos tres ámbitos, la comprensión artística aumenta con la edad hasta los 14 años para nuevamente descender a los 15 años, lo que muestra cierta inconsistencia en el desarrollo de la comprensión artística (cf. fig. 1), desarrollada aparentemente de forma autónoma al desarrollo intelectual y personal de los jóvenes.

Una cuarta dimensión de la comprensión artística, las relaciones que el espectador establece de las imágenes con experiencias personales y vitales (la comprensión artística biográfica), también se desarrolla de acuerdo con la edad, aunque en este caso lo haga de modo progresivo y constante entre los diez y los 15 años, en congruencia con la hipótesis de investigación.

La quinta dimensión establecida en la comprensión artística (comprensión estética) presenta idénticas puntuaciones en los tres grupos de edad con lo que no es posible establecer relaciones significativas en este ámbito de la comprensión en función de la edad.

Una posible explicación a este descenso en la comprensión artística en los tres ámbitos mencionados (histórico, social y pedagógico) en el último grupo de edad (15-17 años), puede ser que, según la investigación previa, la comprensión artística tiene que ver con la atribución de significados a las imágenes en función de las experiencias vitales de los sujetos, por lo que dicha comprensión no mantiene una relación directa con el desarrollo intelectual y artístico de los jóvenes.

Es posible también que haya influido el tamaño de la muestra del grupo de 1517 años que ha respondido al cuestionario sobre comprensión de las imágenes, sensiblemente inferior al resto, debido quizá a una mayor desidia y reticencia de los jóvenes de este grupo de edad a participar en este tipo de estudios.

Asimismo, las cinco dimensiones de la comprensión señalan mejores niveles para las chicas que para los chicos, soportando estudios anteriores (Pavlou y Kambouri, 2007), que señalan mejor rendimiento y mejores competencias artísticas entre ellas.

Como segunda reflexión, los resultados obtenidos en el presente trabajo permiten establecer relaciones relevantes entre la comprensión artística, la competencia artística y la calificación en la asignatura de educación artística, tal y como estudios previos (Pavlou y Kambouri, 2007) han evidenciado, si bien es necesario precisar el sentido de dichas relaciones, por cuanto la percepción que los jóvenes poseen sobre las propias destrezas artísticas (la competencia artística autopercibida) es menor entre los jóvenes con mayores niveles de comprensión artística, siendo los estudiantes de arte con menores niveles de comprensión los que poseen una más positiva percepción de sus capacidades y de sus destrezas artísticas.

Por otro lado, el denominado logro artístico (la calificación en la asignatura de Educación Plástica y Visual), se relaciona positivamente con la comprensión artística, aspecto este último marginal en los currículos de enseñanza artística básica, que se centran sobre todo en el desarrollo de destrezas manipulativas ajenas a la reflexión y al conocimiento (Moreno, 2012). 


\section{Conclusiones}

El presente estudio ha cumplido en parte los objetivos planteados en un principio. En relación al primer objetivo, ha sido posible identificar los cinco ámbitos propuestos por la investigación previa (Sueli, 2002) para la comprensión en educación artística, y lo ha hecho de modo favorable para las chicas, si bien sólo cuatro (histórico, social, pedagógico, biográfico) de los cinco ámbitos han permitido establecer diferencias significativas entre los estudiantes según la edad. El desarrollo de la comprensión artística en función de la edad ha sido irregular en este trabajo y los resultados no soportan totalmente investigaciones previas que habían encontrado desarrollo comprensivo en paralelo al desarrollo general de los jóvenes (Anderson y Hanson, 2010). Se considera preciso, a partir del presente trabajo, establecer una más precisa definición de la comprensión artística y de los factores que la conforman.

El segundo objetivo del presente estudio ha sido también parcialmente completado, pues se ha establecido una correlación de signo positivo entre la comprensión artística, la competencia artística que se atribuyen a sí mismos los estudiantes y el resultado académico en clase de educación artística; ahora bien, son, en contra de lo esperado, los estudiantes con unos niveles de comprensión artística más alta los que tienen una menor confianza en sus propias competencias artísticas. Este resultado exige nuevas investigaciones en este sentido con el fin de averiguar si se trata de que elevados niveles de comprensión artística sobre los hechos del entorno supongan una mayor incertidumbre para chicos y chicas acerca de las propias destrezas artísticas. Se debe avanzar en la búsqueda de una más precisa definición de la comprensión artística y de sus ámbitos para aclarar estas inconsistencias.

Por su parte, la relación positiva entre comprensión artística y calificación en arte que los resultados desvelan, plantea la posibilidad de que, más allá de ciertas destrezas mecánicas, la propia área de educación artística incida, más de lo esperado, en el desarrollo de capacidades comprensivas de los hechos visuales del entorno, a la vez que se incide desde las escuelas en obtener un rendimiento académico óptimo que permita a los estudiantes desarrollarse personal e intelectualmente, a partir de un currículo escolar no siempre atento a la formación artística de los adolescentes.

Este estudio ha pretendido desarrollar planteamientos previos (Sueli, 2002) de la educación artística comprensiva, combinando factores del rendimiento académico de la escuela tradicional (la calificación en el área), junto con otra serie de factores que señalan desempeños reflexivos y significativos en el alumnado (la comprensión artística), combinando estos dos factores con características afectivas del propio alumnado (la competencia artística que cada estudiante se atribuye a si mismo).

Más allá de las limitaciones referidas a la falta de antecedentes de investigaciones de este tipo en el área, este trabajo avanza en la conceptualización de la comprensión del entorno por parte de los jóvenes contemporáneos, comprensión que realizan, principalmente, a partir de imágenes siempre presentes.

Los jóvenes interpretan los hechos visuales a los que se enfrentan dotando de sentido a aquello que perciben mediante el establecimiento de relaciones entre las imágenes que les rodean y sus propias experiencias vitales, por lo que, más allá del descubrimiento de estructuras simbólicas y formales dispuestas por el autor de las imágenes, el espectador busca explicar su propia existencia a partir de los 
testimonios circundantes que en gran medida toman forma de imágenes que se erigen en testigos del acontecer diario. La extrapolación flexible, activa y necesaria a la propia experiencia personal y cultural de cada joven de esa realidad representada es lo que se entiende como comprensión artística, la cual permite reconocerse en cada momento y reconocer el sentido de las relaciones con el entorno en términos ideológicos, económicos, históricos, sociales y culturales.

\section{Referencias}

Anderson, D., y Hanson, K. H. (2010) From blooming, buzzing confusion to media literacy: the early development of television viewing. Developmental Review 30, 239-255.

Aznárez, J. P. (2008) Visualidad expandida y construcción de narrativas. Nuevas posibilidades para la Educación Artística. Red Visual, 8, 1-9.

Barbosa, B. (2005). Lecturas de imágenes y metodologías en educación artística. Arte. Individuo y Sociedad, 17, 7-16.

Beilin, R. (2005) Photo-elicitation and the agricultural landscape: 'seeing' and 'telling' about farming, community and place. Visual Studies 20(1), 56-68.

Bernardo, V., y Sueli, T. (2009). Un instrumento de mediación para una comprensión crítica del Arte: Guernika (re)visitada. Invisibilidades, 0, 73-85.

Buxkemper, A. C., y Hartfiel, D. J. (2003). Understanding. International Journal of Mathematical Education in Science and Technology 34(6), 801-812.

Chamorro-Premuzic, T., y Furnham A. (2008) Personality, Intelligence and Approaches to Learning as Predictors of Academic Performance. Personality and Individual Difference, 44(7): 1596-1603.

Chamorro-Premuzic, T., Harlaar, N., Greven, C., y Plomin, R. (2010) More than just IQ: A longitudinal examination of self-perceived abilities as predictors of academic performance in a large sample of UK twins. Intelligence, 38(4), 385392.

Colom, R., Escorial, S., Chun Shih, P., y Privado, J. (2007) Fluid Intelligence, Memory Span, and Temperament Difficulties Predict Academic Performance of Young Adolescents. Personality and Individual Differences, 42(8), 1503-1514.

Gabrelian, N., Blumberg, F., y Hogan, T. (2009) The Effects of Appeal on Children's Comprehension and Recall of Content in Educational Television Programs. Journal of Applied Developmental Psychology, 30(2), 161-168.

Guay, F., Ratelle, C., Roy, A., y Litalien, D. (2010)Academic self-concept, autonomous academic motivation, and academic achievement: Mediating and additive effects. Learning and Individual Differences, 20, 644-653.

Hetland, L., Hammerness, K., Unger, C., y Wilson, D. (1997) How Do Students Demonstrate Understanding? En M. Wiske (comp.) Teaching for Understanding: Linking Research with Practice (pp. 257-297). Hoboken, NJ: Jossey-Bass Publishers.

Kim, M., y Song, J. (2010) A Confirmatory Structural Equation Model of Achievement Estimated by Dichotomous Attitudes, Interest, and Conceptual Understanding. Eurasia Journal of Mathematics, Science y Technology Education, 6(4), 271-285. 
Kornilova, T., Kornilov S., y Chumakova, M. (2009) Subjective Evaluations of Intelligence and Academic Self-concept Predict Academic Achievement: Evidence from a Selective Student Population. Learning and Individual Differences, 19(4), 596-608.

Laborde, S., Dosseville, F., y Scelles, N. (2010) Trait emotional intelligence and preference for intuition and deliberation: respective influence on academic performance. Personality and Individual Differences, 49, 784-788.

Logan, S., Medford, E., y Hughes, N. (2010) The Importance of Intrinsic Motivation for High and Low Ability Readers' Reading Comprehension Performance. Learning and Individual Differences, 21(1), 124-128.

Moreno, M. (2012). El conocimiento artístico y visual y el currículo. Red Visual, 16, 33-44.

Norusis, M. (2002). SPSS 11.0 Guide to Data Analysis. NJ: Prentice Hall.

Pavlou, V., y Kambouri, M. (2007) Pupils' attitudes towards art teaching in primary school: an evaluation tool. Studies in Educational Evaluation, 33(3-4), 282-301.

Perkins, D. (1997) What is Understanding? En M. Wiske (comp.) Teaching for Understanding: Linking Research with Practice (pp. 69-92). Hoboken, NJ: Jossey-Bass Publishers.

Sueli, T. (2002) Educación para la Comprensión Crítica del Arte. Un Modelo de Análisis. Arte, Individuo y Sociedad, 14, 27-47.

Tanilon, J., Segers, M., Vedder, P., y Tillema, H. (2011) Incremental validity of a performance-based test over and above conventional academic predictors. Learning and Individual Differences, 21(2), 223-226.

Urdan, T., y Schoenfelder, E. (2006) Classroom Effects on Student Motivation: Goal Structures, Social Relationships and Competence Beliefs. Journal of School Psychology, 44(5), 331-349.

Yates, L. (2010) The story they want to tell, and the visual story as evidence: young people, research authority and research purposes in the education and health domains. Visual Studies, 25(3), 280-291. 